\title{
Gating system design for the space device case using T-Flex CAD
}

\author{
Munkhe-Zul Ayusheev ${ }^{1, *}$, and Tamara Kostyuchenko ${ }^{1}$ \\ ${ }^{1}$ Tomsk Polytechnic University, 634050 Tomsk, Russia
}

\begin{abstract}
The judicious selection of gating system for the consumable pattern takes a lot of time, labour and other significant resources. The modern design technologies provide quick and effective ways for gating system calculation and casting process simulation. Gating system modeling allows estimating different kinds of defects which can occur at the developing stage of casting process. Moreover, it is possible to modify the whole gating system configuration if some parameters are changed. Analyzing these data and modifying the gating system characteristics high quality of castings can be achieved.
\end{abstract}

\section{Introduction}

Casting is a very crucial manufacturing process for the production of space devices because many of them have cast details. Casting is one of the most economic and efficient method. But, design calculation of the gating system with necessary characteristics to cast product takes a lot of time [1-9].

The modern parametric T-Flex CAD [5-6] .system which was developed by Top Systems Ltd. (Moscow, Russia) can carry out a number of problems and accelerate the process of the gating system design significantly. T-Flex CAD affords an opportunity to modify the whole configuration changing only one or several gating system geometrics, at the same time providing calculations of the necessary parameters depending on the model geometry.

The main results of the gating system design calculation for the space device case using T-Flex CAD are provided. Figure 1 shows 3D model of the developed device case.
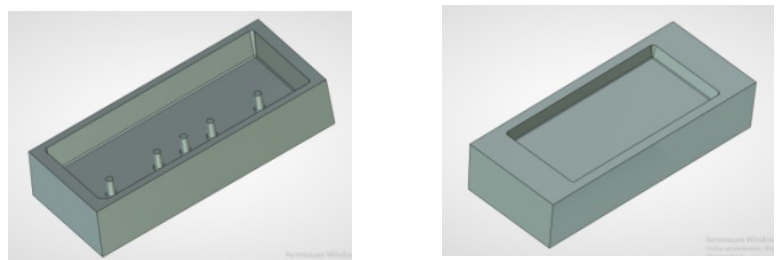

Fig. 1.3D model of the developed device case.

\footnotetext{
*Corresponding author: muncko94@mail.ru
} 


\section{Materials and methods}

Initial data for the casting:

- It should be a sand-mold casting;

- Device case material - aluminium alloy AK7;

- Device case dimensional specifications $820 \times 350 \times 170 \mathrm{~mm}$;

- Pure casting mass $-50 \mathrm{~kg}$.

According to standard methods for the gating system design we should follow by the next steps [7-9]:

1. Choosing the casting position in a mould, mould joint, casting head height and type of the gating system (pouring temperature for the aluminium alloy AK7 is equal to $710{ }^{\circ} \mathrm{C}$ ).

2. The typical configuration L-1A of the gating system was chosen [7]. Further, the length of runner branch, number of gates, and sprue position on the runner should be determined. For the device case the length of runner branch should be $L_{r}=90 \mathrm{~cm}$; number of gates $n=16$; sprues will be placed one by one at the each edge of runner.

3 . Based on the casting mass and height, gating ratio $F_{s}: F_{r}: F_{g}=1: 2: 4$ [7] is set approximately, where $F_{s}: F_{r}: F_{g}-$ total cross-sectional area of sprues, runners and gates. Sprue diameter will be equal to $1 \mathrm{~cm}$.

According to initial data for the device case (Figure 1), the parametric 3D model of the gating system was created using T-Flex CAD facilities. This model is shown in Figure 2.

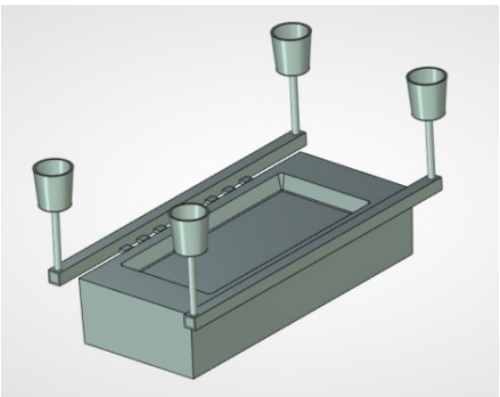

Fig. 2. 3D model of the designed gating system.

The parametric gating system model includes all calculated parameters which depend on the geometrics. Calculation in the T-Flex CAD system is based on data which were introduced in the built-in variable editor.

The cross-sectional area and perimeter at the liquid metal entrance level is defined preliminary. This case, the cross-sectional area is equal to $S_{c}=646 \mathrm{~cm}^{2}$ and perimeter $P=$ $435 \mathrm{~cm}$.

The primary hydrostatic head is determined as:

$$
H_{0}=h_{s}+h_{l},
$$

where $h_{s}$ is the sprue height, $h_{l}$ is the liquid metal level into the pouring basin. An average head can be calculated by the formula:

$$
H_{a}=H_{0}-\frac{h_{c}}{2}
$$

where $h_{c}$ is the casting height from the gate level.

The primary and average heads are identical and equal to $24,5 \mathrm{~cm}$ as the top gate was chosen, the casting height is equal to zero. 
The sprue height is equal to $h_{s}=16,5 \mathrm{~cm}$. On the assumption of dependence between sprue and basin heights, the height of last is equal to $H_{b}=10 \mathrm{~cm}$ [7]. The liquid metal level in the basin is set to $h_{l}=8 \mathrm{~cm}$.

For the filling calculation, the average rate of the liquid metal fills the mould cavity is determined by the following formula:

$$
v_{a}=\frac{Q_{\max } \cdot \sqrt{H_{a}}}{S_{c} \cdot \sqrt{H_{0}}},
$$

where $Q_{\max }$ is the maximum allowable consumption.

The average liquid metal fills the mould cavity is equal to $1,68 \mathrm{~cm} / \mathrm{sec}$.

At calculations, it is necessary to keep the filling criterion: the average filling rate has to be more than minimum allowable filling rate.

The vertical walls of the device case which have the thickness about $27 \mathrm{~mm}$ will be the most dangerous zones for filling. According to special reference data [7], the minimum filling rate for vertical walls with such thickness $(\delta=27 \mathrm{~mm})$ and height $(h=180 \mathrm{~mm})$ will be $v_{\text {fmin }}=0,52 \mathrm{~cm} / \mathrm{s}$. The calculated average filling rate $v_{a}=1,68 \mathrm{~cm} / \mathrm{s}$ is more than minimum allowable rate, therefore, the filling criterion is observed.

The calculated flow rate of liquid metal through the sprue is determined by the monogram at the $d_{l . s .}=1 \mathrm{~cm}, H_{0}=24,5 \mathrm{~cm}, L_{r}=90 \mathrm{~cm}, \mathrm{n}=16, F_{s}: F_{r}: F_{g}=1: 2: 4$ and $t_{p}=$ $710^{\circ} \mathrm{C}$, where $d_{l . s .}$ is the sprue diameter in the lower section, $t_{p}$ is the pouring temperature. The calculated flow rate of liquid metal is equal to $v_{s}=1,5 \mathrm{~m} / \mathrm{s}$. Such rate is less than maximum allowable rate for the sprue with diameter $10 \mathrm{~mm}$ [7].

After the diameter setting at the lower section it is necessary to calculate the diameter at the upper section of sprue by the next formula:

$$
d_{u . s}=d_{l . s}+1,5 \frac{h_{s}}{100}
$$

The number of sprues is determined from the total cross-sectional area of sprues. Accepting the number of sprues is four; diameter of each sprue will be $1 \mathrm{~cm}$ at the lower section and $1,3 \mathrm{~cm}$ at the upper section.

Calculation of the actual flow rate of liquid metal through the runner is determined by the following formula:

$$
v_{r}=v_{s} \cdot \frac{F_{s}}{F_{r}},
$$

where $v_{s}$ is the flow rate of liquid metal through the sprue.

The actual flow rate of liquid metal through the runner is equal to $75 \mathrm{~cm} / \mathrm{s}$.

The runner sizes issue from the runner total cross-sectional area. Consequently, it is possible to accept two runners with identical sizes in cross-sectional geometry for the developing gating system: $a=2,5 \mathrm{~cm}, b=2,5 \mathrm{~cm}$ : the runner length was determined above.

As $v_{r}<v_{r \text { max }}$, the condition of liquid metal passing through the runner will be observed [7].

Taking into account that $F_{g}=4 \cdot F_{s}$ and accepted number of gates is $n=16$, the area of choke can be found as $f_{g}=\frac{F_{g}}{n}$. The choke area is equal to $f_{g}=1,8 \mathrm{~cm}^{2}$. 
The setting gates thickness is equal to $\delta_{g}=0,7 \mathrm{~cm}$ that meet a requirement $\frac{h_{r}}{\delta_{g}} \geq 3,25, h_{r}$ is the runner height. The choke width can be found as $c=\frac{f_{g}}{\delta_{g}}$. And the choke width is equal to $c=2,6 \mathrm{~cm}$. The actual flow speed in gates can be determined as $v_{g}=v_{s} \cdot \frac{F_{s}}{F_{g}}$.

The actual flow rate of liquid metal through the gates will be equal to $v_{g}=41 \mathrm{~cm} / \mathrm{s}$.

The maximum allowable rate $v_{g \cdot \max }=\frac{12}{R_{g}}$. The maximum allowable rate is equal to $v_{\text {g.max }}=48.7 \mathrm{~cm} / \mathrm{s}$.

As the actual rate is less than maximum allowable rate, passing through the gates is provided.

The distance between the sprue and first gate can be calculated as $L_{g}=0,147 \cdot h_{r} \cdot v_{r}$. This distance will be equal to $L_{g}=28 \mathrm{~cm}$.

The calculated parameters meet the all requirements for the gates. Gates has a uniform distribution at the perimeter keeping the distance between the first gate and sprue.

The volume of the filled basin is calculated by the following formula: $V_{b}=1,5 \cdot Q_{\max }$ and this parameter is equal to $1631 \mathrm{~cm}^{3}$.

The calculations of all described parameters were carried out by using built-in variable editor in the T-Flex CAD system. Changing of the gating system geometrics all parameters will be re-computed for the new configuration automatically.

\section{Conclusions}

Using T-Flex CAD, the gating system for the space device case (Figure 1) was completely designed and calculated; 3D model of the device case and gating system are parametrically connected. It gives the possibility to have only one case model to receive alternative case configurations with different sizes and automatically reconstruct the gating system model using the new case geometrics.

Such method of the gating system design significantly accelerates designing process and gives the high quality of casting. Besides, the gating system model can be used for further researches by casting process simulation tools.

\section{References}

1. V. Dmitriev, Y. Britova, MATEC Web of Conf. 48, 01005, (2016)

2. A. Swapnil, S.B. Ambekar Dr., Jaju Int. J. Eng. Res. and Gen. Scien. 2, 93 (2014)

3. N.A. Kupriyanov, F.A. Simankin, K.K. Manabaev, IOP Conference Series: Materials Science and Engineering 124 (1), 012100 (2016).

4. F.A. Simankin, G.R. Ziyakaev, I.V. Kuznetsov, R.E. Lushnikov, IOP Conference Series: Materials Science and Engineering 124 (1), 012072 (2016)

5. Yu. Britova, V. Dmitriev, T. Kostyuchenko, IOP Conference Series: Materials Science and Engineering 132(1), 012011 (2016)

6. A.V. Taracenko, V.S. Dmitriev, T.G. Kostuchenko, KORUS, 83 (2004) 
7. N. Galdin, Litnikovye sistemy dlja otlivok iz legkih splavov (Mashinostroenie, Moscow, 1978) (in Russian)

8. V. Anjo, R. Khan, J. of Practices and Technologies 23, 45 (2013)

9. B. Vijaya Ramnath et al. Procedia Materials Science 6, 1312 (2014) 